\title{
Reduced collagenolytic activity of matrix metalloproteinases and development of liver fibrosis in the aging rat
}

\author{
Nicoletta Gagliano a, Beatrice Arosio a, Fabio Grizzi ${ }^{\text {c, Serge Masson }}{ }^{\text {d, }}$ \\ Jacopo Tagliabue a, Nicola Dioguardi ${ }^{\text {c }}$, Carlo Vergani ${ }^{\text {a }}$, Giorgio Annoni ${ }^{\text {a,b,* }}$ \\ a Department of Internal Medicine and Geriatrics, Milan University and Ospedale Maggiore IRCCS, Via Pace 9, 20122, \\ Milan, Italy \\ ${ }^{\mathrm{b}}$ Milan-Bicocca University, Milan, Italy \\ ${ }^{\mathrm{c}}$ Scientific Direction, Istituto Clinico Humanitas, Rozzano Milan, Italy \\ d Department of Cardiovascular Research, Istituto di Ricerche Farmacologiche 'Mario Negri', Milan, Italy
}

Received 9 May 2001; received in revised form 4 October 2001; accepted 5 October 2001

\begin{abstract}
Although moderate fibrosis is a histological hallmark of the aging liver, the molecular mechanisms underlying this phenomenon are little known. Here, we provide a comprehensive description of hepatic collagen expression and metabolism during natural aging in rats. Interstitial collagen accumulated significantly in the oldest animals, mainly in the periportal area $(P<0.05,19-$ vs. 2 -month-old rats). This was ascribed to COL-III protein deposition $(P<0.05$ vs. 2-month-old rats), rather than COL-I. Conversely, the transcription activity of COL-III gene decreased $(P<0.05)$ during the considered lifespan (2-19-months), whereas COL-I and transforming growth fator- $\beta 1$ (TGF- $\beta 1$ ) mRNA content was substantially unchanged. In the aged rats, hepatic matrix metalloproteinases (MMP) activity, (both MMP-1 and MMP-2) dropped significantly $(P<0.05)$, with a concomitant increase of the inactive tissue inhibitor of MMP (TIMP-1)/MMP-1 complex $(P<0.05)$. MMP-2 and TIMP-1 levels were weakly affected. All together, these results suggest that during natural aging, (i) COL III is the protein that accumulates preferentially in the liver; (ii) liver fibrosclerosis is mainly explained by a reduced proteolytic activity of matrix MMP, in which TIMP-1 seems to be a major regulating factor. (c) 2002 Elsevier Science Ireland Ltd. All rights reserved.
\end{abstract}

Keywords: Liver; Aging; Fibrosis; Matrix metalloproteinases

\section{Introduction}

Aging affects the organs, tissues, and cell types of the same organism in different ways, resulting

\footnotetext{
* Corresponding author. Tel.: + 39-02-55035357; fax: + 3902-55017492.

E-mail address: giorgio.annoni@unimib.it (G. Annoni).
}

in differential rates of decline of function, but all together concurring to the diminished ability to meet increased demand. Thus, not all organs are equally involved and morpho-functional studies suggest that, compared with others, the liver seems to age fairly well. Although, the liver is not exempt from age-related morphological changes, its homeostatic functions are not seriously im- 
paired, and liver function tests remain normal in senescent individuals (Schmucker, 1998; Schuppan, 1990; Tietz et al., 1992). Several studies, mostly on animal models, indicate that the most frequent age-dependent changes are the reduction in organ mass, hepatocyte enlargement and degeneration, the increase in individual mitochondrial volume and the decline in their number, bile duct proliferation and, above all, variable degrees of fibrosis (Grasedyck et al., 1980; Sakai et al., 1997; Sastre et al., 1996).

Fibrosis is a hallmark of the aging of various organs, including the heart and kidney (Abrass et al., 1995; Annoni et al., 1997; Gagliano et al., 2000), and reflects increased deposition of the physiological components of the extracellular matrix (ECM). The liver ECM is not only a passive structural support, since it plays key roles in providing a structural framework and maintaining the differentiated phenotype and normal function of hepatocytes, sinusoidal endothelial and stellate cells (Martinez-Hernandez, 1984; Martinez-Hernandez and Amenta, 1993). ECM turnover is a vital step in the tissue remodeling that accompanies physiological and pathological processes, so any quantitative changes can result in deranged hepatic function.

Collagens (COL) are the major components of liver ECM (Martinez-Hernandez and Amenta, 1993). In the normal liver, interstitial COL types I and III are present in approximately equal quantities, constituting about $80 \%$ of the total (Biagini and Ballardini, 1989) and are mainly located within portal areas (Martinez-Hernandez and Amenta, 1993; Rojkind et al., 1979). COL content is governed by the balance between synthesis and degradation, with a rapid turnover (Laurent, 1987; Mays et al., 1991a). Much of the newly synthetized COL is immediately degraded, the extent of this process being primarily regulated by the metalloproteinases (MMP), whose activity under physiological conditions is precisely regulated, (a) at the level of gene expression, including transcription (Angel et al., 1987) and translation (Brinckerhoff et al., 1986); (b) at the level of activation; or (c) at the step of inhibition by MMP tissue inhibitors (TIMP) (Herron et al., 1986). Lasting perturbations of any of these steps can lead to liver fibrosis. The cellular and molecular events underlying fibrogenesis during pathological conditions have been investigated (Czaja et al., 1989; Milani et al., 1994) but so far little data is available about the changes in hepatic COL metabolism during aging (Bradley et al., 1974; Schaub, 1963).

The aim of this study was to provide a comprehensive description of hepatic COL expression and metabolism during natural aging in rats. We first documented that COL deposition in the aging liver was predominantly due to an accumulation of COL-III protein in the periportal compartment, even though the transcription activity of this gene was down regulated. In fact, we report here for the first time, that the net balance for COL metabolism, in favor of accumulation during aging, was explained by a reduced proteolytic activity of MMP.

\section{Materials and methods}

\subsection{Animals}

Twenty male Sprague-Dawley rats (Iffa Credo S.A., a Charles River company, Calco, Italy) were studied at 2, 6, 12 and 19-months of age (five animals per age group). On arrival, rats were individually housed for 15 days, with controlled temperature $\left(25^{\circ} \mathrm{C}\right)$ and a 12 -h alterned lightdark cycle, then weighed, and killed under fentanyl anaesthesia. Procedures involving animals and their care were conducted in conformity with the institutional guidelines in compliance with international policies (EEC Council Directive 86/ 609, OJ L 358, 1, 12 December 1987).

The liver was removed, weighed, immediately frozen in liquid nitrogen and stored at $-80{ }^{\circ} \mathrm{C}$, except for a portion cut out for histology.

\subsection{Quantification of $m R N A$ levels}

Total RNA was extracted from approximately $100 \mathrm{mg}$ of frozen tissue by the acid guanidinium thiocyanate-phenol-chloroform method (Chomczynski and Sacchi, 1987). RNA purity and concentration were determined spectro- 
photometrically. Total RNA was analyzed by Northern blot to assess the specific hybridization with each cDNA probe, followed by Slot hybridization assays for quantitative evaluation. For Northern blot, $30 \mu \mathrm{g}$ samples were denatured and electrophoresed through $1 \%$ agarose gels. RNA integrity was verified by examining the $28 \mathrm{~S}$ and $18 \mathrm{~S}$ ribosomal RNA bands of ethidium bromide stained gels under ultraviolet light. RNA was transferred to a nylon membrane (Gene Screen, New England Nuclear, Du Pont, Italy) overnight by capillary blotting and backed at $80{ }^{\circ} \mathrm{C}$ for $2 \mathrm{~h}$.

For Slot blot analysis total RNA $(10,4,2 \mu \mathrm{g})$ was denatured in 50\% DMSO, $10 \mathrm{mM} \mathrm{NaH} \mathrm{PO}_{4}$ $\mathrm{pH}$ 7, $1 \mathrm{M}$ glyoxal for $1 \mathrm{~h}$ at $50{ }^{\circ} \mathrm{C}$, applied directly to Z-probe membranes (Bio Rad, Italy) under gentle vacuum, and fixed at $80{ }^{\circ} \mathrm{C}$ for $1 \mathrm{~h}$. cDNA probes for rat pro- $\alpha 2(\mathrm{I})$ collagen (COL-I) (American Type Tissue Collection, ATCC), rat pro- $\alpha 1$ (III) collagen (COL-III) (kindly provided by Dr E. Vuorio, University of Turku, Finland), swine TGF- $\beta 1$ (ATCC) were labeled with ${ }^{32} \mathrm{P}$ dCTP (Amersham Pharmacia Biotech, Italy) by primer extension (Random Primed DNA labeling kit, Roche, Italy). Membranes were prehybridized for $16-18 \mathrm{~h}$ in a solution containing $50 \%$ formamide, $5 \times \mathrm{SSC}, \quad 1 \% \quad \mathrm{SDS}, \quad 2 \times$ Denhardt's reagent $(50 \times$ reagent contains $5 \mathrm{~g}$ Ficoll, $5 \mathrm{~g}$ polyvinylpyrrolidone, $5 \mathrm{~g}$ bovine serum albumin, BSA). Hybridization was done in the same solution, with $2-3 \times 10^{6} \mathrm{cpm} / \mathrm{ml}$ of ${ }^{32} \mathrm{P}$-labelled cDNA added, for $16-18 \mathrm{~h}$ at $42{ }^{\circ} \mathrm{C}$. Blots were then washed with $2 \times \mathrm{SSC}$ at room temperature, $2 \times \mathrm{SSC} 0.5 \% \mathrm{SDS}$ at $65{ }^{\circ} \mathrm{C}, 0.1 \times \mathrm{SSC}$ at room temperature, $0.1 \times \mathrm{SSC} 0.1 \%$ SDS $0.1 \%$ sodium pyrophosphate at $55{ }^{\circ} \mathrm{C}$, and exposed for $1-7$ days at $-80{ }^{\circ} \mathrm{C}$ to autoradiographic films in cassettes with intensifying screens (Sambrook et al., 1989).

The filters were hybridized with a glyceraldehyde 3-phosphate dehydrogenase (GAPDH) cDNA probe (Clontech, Becton Dickinson, Italy), a rat housekeeping gene, to normalize the results. Messenger RNA signals on autoradiographs were quantified by laser densitometry (IM1D, Amersham Pharmacia Biotech, Italy).

\subsection{Histochemistry and image analysis}

\subsubsection{Sirius red staining}

Specimens were fixed in 10\% formalin and embedded in Paraplast (Oxford Labware, England). Five-micrometer thick sections were mounted on glass slides, deparaffinized and immersed for 15 min in saturated aqueous picric acid containing $0.1 \%$ Sirius Red F3BA (Sigma, Italy), a stain specific for collagen. With this method collagenous proteins stain distinctly red. For each sample the collagenous deposits were taken at $20 \times$ magnification on centrilobular fields of the hepatic acinus, and on surrounding terminal hepatic veins. In order to avoid possible bias due to the sampling of the individual fields, for every specimen we analyzed at least 15 fields containing a centrilobular vein and the same was done for the portal tracts. All the samples were evaluated in blind by one of us (Fabio Grizzi).

\subsubsection{Image analysis}

The images were captured and digitized using an image analysis system consisting of an Axiophot light microscope (Zeiss, Germany), a video camera-3CCD (KY-F55BE, JVC, Italy) that transmits image data to a PC with a Pentium-S $133 \mathrm{MHz}$ processor (Intel Corporation, Santa Clara, California, USA), an incorporated framegrabber board (Imascan, USA), and specific software (Computer Liver, Ansible, Italy) (Dioguardi et al., 1999). The image intensity level was kept the same throughout the study. The specific software automatically selects the collagenous portion on the basis of similarities in the color of adjacent pixels, which are then converted to one (black-and-white) or binary images. The surface area covered by collagen tissue is automatically evaluated and expressed as the fibrotic area (\%), calculated as a ratio of the Sirius positive area to the total area examined and averaged on the number of the considered fields.

\subsection{Hydroxyproline}

The frozen samples were homogenized and hydrolyzed in $6 \mathrm{~N} \mathrm{HCl}$ for $24 \mathrm{~h}$ at $110{ }^{\circ} \mathrm{C}$; PRO-OH 
was measured spectrophotometrically on the basis of its reaction with Ehrlich's reagent, using the methods described by Stageman and Stalder (Stageman and Stalder, 1967).

\subsection{Collagen type I and III expression}

\subsubsection{Neutral salt extraction of collagen}

Liver samples were homogenized in ice cold extraction buffer ( $1 \mathrm{ml} / 100 \mathrm{mg}$ tissue) containing Tris $-\mathrm{HCl} 50 \mathrm{mM} \mathrm{pH} \mathrm{7.5,} \mathrm{NaCl} 100 \mathrm{mM}$, $\mathrm{CaCl}_{2} 2 \mathrm{mM}$ and freshly added proteases inhibitors (aprotinin $1 \mu \mathrm{g} / \mathrm{ml}$, leupeptin $10 \mu \mathrm{g} / \mathrm{ml}$, pepstatin A $1 \mu \mathrm{g} / \mathrm{ml}$, PMSF $2 \mathrm{mM}$ ). The homogenate was centrifuged $\left(4{ }^{\circ} \mathrm{C}, 10 \mathrm{~min}, 1500 \times\right.$ $g$ ), the supernatant decanted and saved on ice. The final concentration of the liver extracts was determined with a standardized colorimetric assay (DC Protein Assay, Bio Rad, Italy), and the samples were divided into aliquots and stored at $-20{ }^{\circ} \mathrm{C}$.

\subsubsection{Dot blot and immunoassay}

One hundred micrograms of total protein extracts for each sample in a final volume of $200 \mu \mathrm{l}$ of TBS were spotted in triplicate on a nitrocellulose membrane placed in a Bio-Dot SF apparatus (Bio-Rad, Italy). After allowing the entire sample to filter through the membrane by gentle vacuum, each sample well was washed with $400 \mu$ of TBS. After a complete draining, the membrane was air dried for $30 \mathrm{~min}$ and then placed in blocking solution for $1 \mathrm{~h}$.

For COL-I determination the membrane reacted with a polyclonal antibody (1:2000) (Chemicon, CA, USA) for $1 \mathrm{~h}$ and with a second antibody conjugate with horseradish peroxidase (1:5000) (Sigma, Italy); the immunoreactive bands were revealed by Amplified Opti-4CN (BioRad, Italy). For COL-III were used a monoclonal antibody (1:2000) (Sigma, Italy) for $1 \mathrm{~h}$ and a horseradish peroxidase conjugated (1:8000) (Sigma, Italy); the signal was revealed by Opti4CN substrate (Bio Rad, Italy). The antibody specificity was assessed on purified COL type I and III (Sigma, Italy) used as positive and negative controls.

\subsection{Collagen degradation}

\subsubsection{MMP and TIMP extraction}

Liver samples were homogenized in an ice-cold extraction buffer $(1 \mathrm{ml} / 100 \mathrm{mg}$ tissue $)$ containing cacodylic acid $10 \mathrm{mM}, \mathrm{NaCl} 150 \mathrm{mM}, \mathrm{ZnCl}_{2} 1$ $\mathrm{mM}, \mathrm{CaCl}_{2} 20 \mathrm{mM}, \mathrm{NaN}_{3} 1.5 \mathrm{mM}$, Triton X-100 $0.01 \%(\mathrm{pH} 5)$. The homogenate was centrifuged $\left(4{ }^{\circ} \mathrm{C}, 5 \mathrm{~min}, 12000 \times g\right)$ and the supernatant decanted and saved on ice. The final concentration of the liver extracts was determined with a standardized colorimetric assay (DC Protein Assay, Bio Rad, Italy), and the samples were divided into aliquots and stored at $-20{ }^{\circ} \mathrm{C}$ (Kleiner and Stetler-Stevenson, 1994). Each sample was run on SDS-PAGE and stained by Coomassie blue to verify that the same amounts of total proteins were loaded in all lanes.

\subsubsection{Zymography (MMP-2 activity)}

Extracts were thawed on ice and mixed 3:1 with substrate gel sample buffer $(10 \%$ SDS, $4 \%$ sucrose, $0.25 \mathrm{M}$ Tris- $\mathrm{HCl} \mathrm{pH} 6.8,0.1 \%$ bromophenol blue). Each sample $(30 \mu \mathrm{g})$ was loaded under non-reducing conditions onto electrophoretic mini-gels (SDS-PAGE) (Laemnli, 1970) containing $1 \mathrm{mg} / \mathrm{ml}$ of type I gelatin (Sigma, Italy). The gels were run at $15 \mathrm{~mA}$ per gel through the stacking phase $(4 \%)$ and at $20 \mathrm{~mA}$ per gel for the separating phase $(10 \%)$, with a running buffer temperature of $4{ }^{\circ} \mathrm{C}$. After SDS-PAGE the gels were washed twice in $2.5 \%$ Triton $\mathrm{X}-100$ for 30 min each, rinsed in water and incubated overnight in a substrate buffer at $37{ }^{\circ} \mathrm{C}$ (Tris- $\mathrm{HCl} 50 \mathrm{mM}$, $\mathrm{CaCl}_{2} 5 \mathrm{mM}, \mathrm{NaN}_{3} 0.02 \%, \mathrm{pH}$ 8). After incubation the gels were stained with Coomassie blue, $30 \%$ methanol, 10\% acetic acid, and destained in $30 \%$ methanol and 10\% acetic acid (Kleiner and Stetler-Stevenson, 1994). The lysis band areas were quantified by densitometric scanning (IM1D, Amersham Pharmacia Biotech, Italy).

\subsection{3. $M M P-1$ and $M M P-2$ Western blot}

Liver extracts were diluted in SDS-sample buffer, loaded on 10\% SDS-PAGE, separated under reducing but not denaturing conditions at 40 $\mathrm{mA}$ according to Laemmli (Laemnli, 1970), and transferred at $100 \mathrm{~V}$ to a nitrocellulose membrane 
in $0.025 \mathrm{M}$ Tris, $192 \mathrm{mM}$ glycine, $20 \%$ methanol, pH 8.3 (Burnette, 1981). After electroblotting, the membranes were air dried and blocked for $1 \mathrm{~h}$. After being washed in PBST, membranes were incubated overnight at $4{ }^{\circ} \mathrm{C}$ in monoclonal antibody to MMP-1 or MMP-2 $(0.5 \mu \mathrm{g} / \mathrm{ml}$ in PBST/ BSA $1 \% / \mathrm{NaN}_{3} 0.02 \%$, Calbiochem, Italy) and, after washing, in HRP-conjugated rabbit antimouse serum (1:80000 dilution, Sigma, Italy). Immunoreactive bands revealed by the Opti-4CN substrate (Amplified Opti-4CN, Bio Rad, Italy) were scanned densitometrically.

\subsubsection{TIMP-1 Western blot}

Samples (40 $\mu \mathrm{g}$ of total proteins) were heat treated $\left(95{ }^{\circ} \mathrm{C}\right.$ for $\left.4 \mathrm{~min}\right)$ in non-reducing SDS sample buffer and subjected to SDS-PAGE on a $12 \%$ polyacrylamide gel run at room temperature. Proteins were electroblotted and the membranes processed as previously described for MMPs. For detection of TIMP-1 filters were incubated for $2 \mathrm{~h}$ with a mouse anti-TIMP-1 antibody (1:200) (Calbiochem, Italy), followed by horseradish peroxidase-conjugated reaction (1:20 000) (Sigma, Italy) for $1 \mathrm{~h}$ and Amplified Opti-4CN (BioRad, Italy).

\subsection{Statistical analysis}

Statistical comparison between experimental groups was done with one-way analysis of variance (ANOVA). Since we were interested in relative changes more than in absolute differences, the raw data shown in the tables and figures were log transformed before the ANOVA was performed. Then, a Dunnett's post-test (2-month age group

Table 1

Rat liver (LW) and body weights (BW) in relation to age.

\begin{tabular}{llll}
\hline $\begin{array}{l}\text { Age } \\
\text { (months) }\end{array}$ & BW (g) & LW (g) & LW/BW $\times 10^{2}$ \\
\hline 2 & $313.00 \pm 33.00$ & $11.18 \pm 1.32$ & $3.98 \pm 0.45$ \\
6 & $541.20 \pm 13.37^{\mathrm{a}}$ & $19.22 \pm 1.03^{\mathrm{a}}$ & $3.56 \pm 0.13$ \\
12 & $608.40 \pm 27.13^{\mathrm{a}}$ & $17.47 \pm 1.15^{\mathrm{a}}$ & $2.86 \pm 0.12^{\mathrm{a}}$ \\
19 & $767.60 \pm 49.56^{\mathrm{b}}$ & $21.23 \pm 1.05^{\mathrm{a}}$ & $2.78 \pm 0.09^{\mathrm{b}}$ \\
\hline
\end{tabular}

\footnotetext{
a $P<0.05$ vs. 2 -month, Dunnett's post-hoc test.

b $P<0.01$ vs. 2 -month, Dunnett's post-hoc test.

Data are mean \pm S.E.M. for five animals per age group.
}

taken as reference group) was carried out. The GRAPHPAD PRISM version 3.0 software package (GRAPHPAD Software, San Diego, CA) was used for the statistical analysis. All results are expressed as mean \pm standard error of the mean (S.E.M.). A $P$ value of $<0.05$ was considered significant.

\section{Results}

\subsection{Liver and body mass}

The liver weights (LW) and body mass (BW) of rats aged 2, 6, 12 and 19-months are presented in Table 1. LW increased with age but proportionally less than body weight, so the ratio of LW to BW progressively declined from 2 to 12-months and remained constant thereafter.

\subsection{Liver gene expression}

During maturation and aging COL-I mRNA slightly tended to increase (ANOVA $P=\mathrm{ns}$ ) in 6 $(+3 \%, P=\mathrm{ns}), 12(+3 \%, P=\mathrm{ns})$ and 19 -monthold rats $(+25 \%, P=\mathrm{ns})$, in comparison to the young ones. However, COL-III mRNA decreased (ANOVA $P=0.0099)$ in $6(-25 \%, P<0.05), 12$ $(-22 \%, P=$ ns $)$ and 19 -month-old rats $(-33 \%$, $P<0.01)$, compared with the 2 -month-old ones.

The age-related changes in the abundance of liver COL-I and COL-III mRNA are presented in Fig. 1a and b. TGF- $\beta 1$ gene transcription was weakly detectable and remained unchanged throughout the observation time (from 2 to 19 month-old: $0.520 \pm 0.068,0.363 \pm 0.028,0.440 \pm$ $0.061, \quad 0.477 \pm 0.078$ normalized densitometric score).

\subsection{Collagen deposition}

\subsubsection{Histology}

Light microscopy of liver sections revealed mild to moderate fibrosis consequent to COL accumulation in portal and centrilobular areas in aged rats (Fig. 2A and B). Interestingly, in these animals COL is frequently detectable in the parenchyma, mainly diffusely along the sinusoidal 


\section{collagen gene expression}
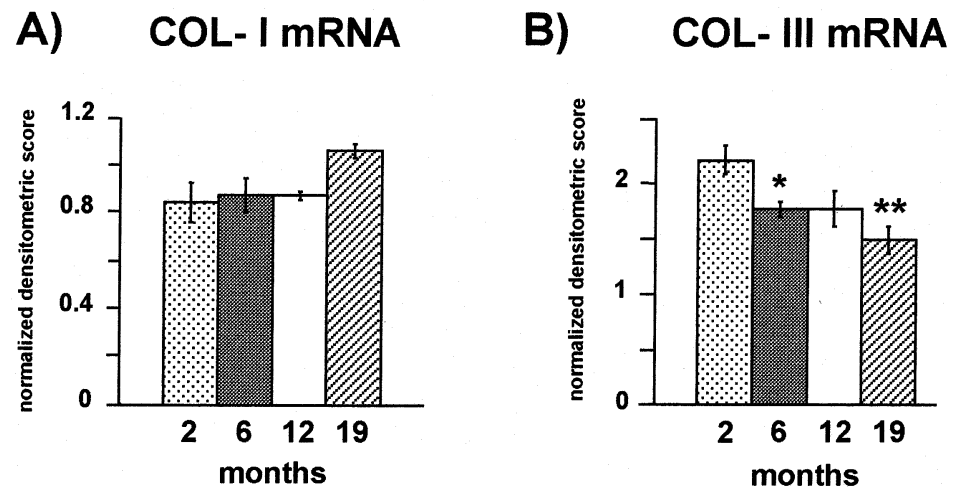

Fig. 1. Bar graph illustrating the age-dependent gene expression of COL-I and COL-III in liver homogenates from rats aged 2, 6, 12 and 19-months. Changes in mRNA signal of pro- $\alpha 2$ (I) collagen (COL-I) (a), pro- $\alpha 1$ (III) collagen (COL-III) (b), are expressed as normalized optical densities relative to GAPDH mRNA. Values are mean \pm S.E.M. (five animals per age group). ${ }^{*} P<0.05$, ** $P<0.01$ vs. 2 -month-old rats.

A)

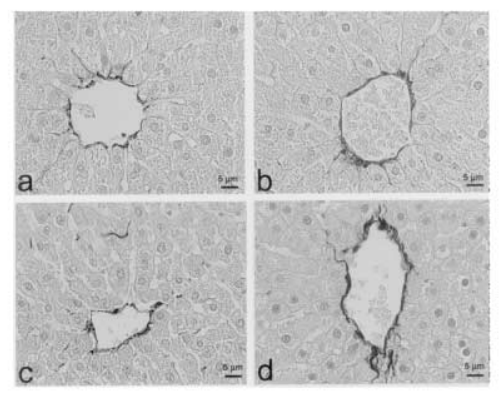

C)

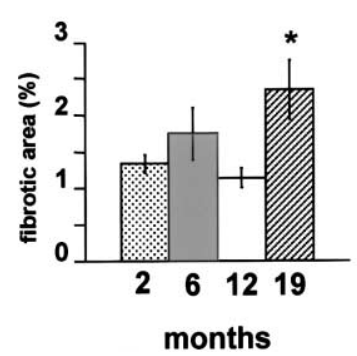

B)

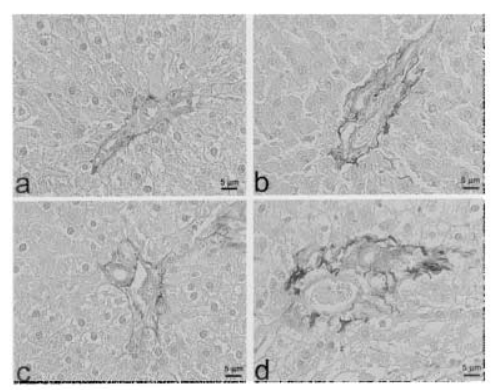

D)

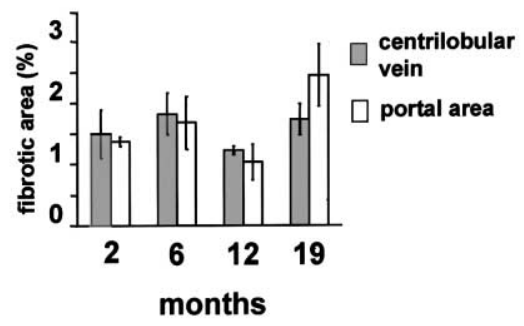

Fig. 2. Microphotographs showing Sirius red staining of liver sections. (A) central vein and; (B) portal areas of rats aged 2 (a); 6 (b); 12 (c); and 19 (d) months. A scale bar shows the magnification. Bar graph illustrating the age-dependent. Morphometric quantification of age-related changes in liver interstitial collagen evaluated by Sirius staining. Data are expressed as total fibrotic area (ratio of the stained area to the total area $\times 100$ ); (C), and as separate collagen evaluation in pericentral and portal areas; (D). Values are mean \pm S.E.M. (five animals per age group). ${ }^{*} P<0.05$ vs. 2 -month-old rats. 


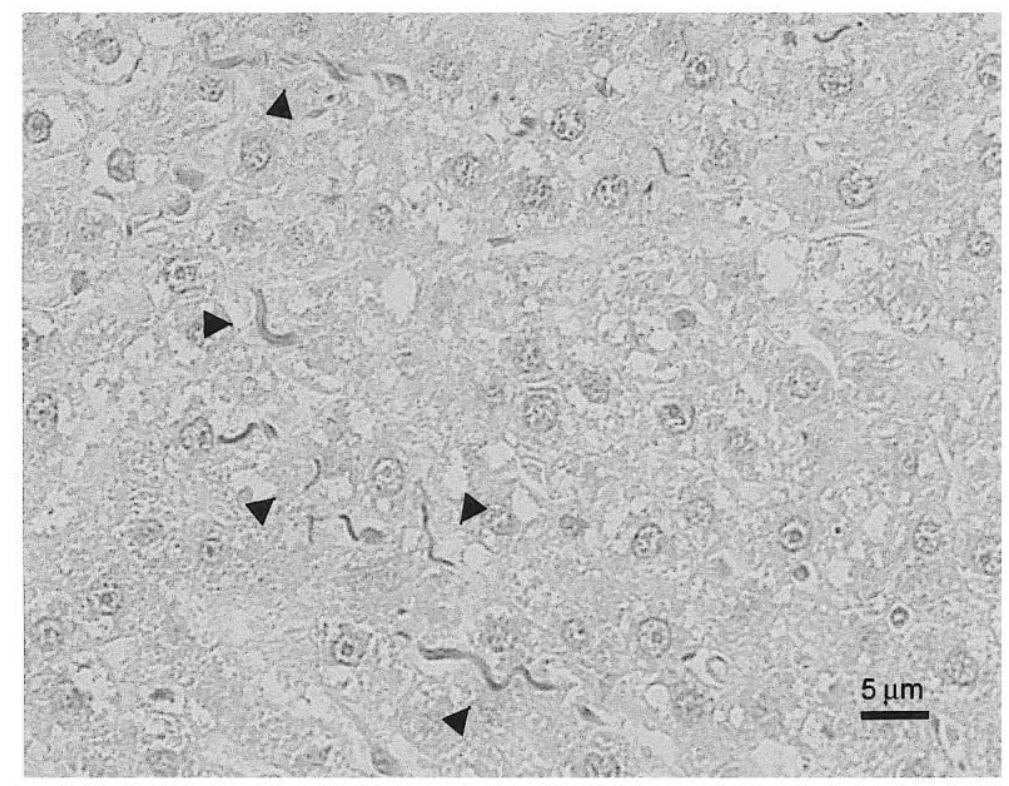

Fig. 3. Microphotograph showing sinusoidal sirius staining (arrows heads) in the liver of a rat aged 19-months. A scale bar points out the magnification.

walls (Fig. 3). Image analysis of Sirius stained sections showed as COL, respectively the 1.25 , $1.25,1.18,2.73 \%$ of the total area in $2,6,12$ and 19-month-old rats, indicating a significant increase in the oldest ones compared with earlier ages $(P<0.05)$ (Fig. 2C).This seems mainly sustained by COL accumulation within the portal tracts: in fact, the increase of the fibrotic area was +34 and $+104 \%$, respectively, around the central veins and within the portal tracts of the oldest rats compared with the young ones (Fig. 2D).

\subsubsection{Hydroxyproline}

Hydroxyproline content (Table 2) was very similar in the animals aged 2, 6 and 12-months, but tended to be higher $(+25 \%, P=\mathrm{ns})$ in the 19 month-old than in the 2-month-old rats.

\subsubsection{Collagen protein types}

Dot blot analysis of collagen revealed a progressive age-dependent deposition only for COLIII. Infact, COL-I was almost unchanged, with a $0,+10,+10 \%$ increase, respectively, in 6,12 and 19-month-old rats compared with the young ones, and for COL-III a $+26 \%(P<0.05),+$
$38 \%(P<0.01),+41 \%(P<0.01)$ increase in 6 , 12 and 19-month-old rats, respectively, compared with 2-month-old ones (Fig. 4).

\subsection{Collagen degradation}

The antibody we used recognized both, latent (57/52 kDa) and active (46/42 kDa) MMP-1. Immunoreactive MMP-1 proenzyme levels were unchanged until 12-months of age and thereafter significantly reduced in the oldest rats $(-25 \%$, $P<0.05$ ), compared with the young ones. Active MMP-1 was lowered by aging, respectively, $-9 \%$ $(P<0.05),-4 \%(P=\mathrm{ns})$ and $-13 \%(P<0.01)$ in the 6,12 and 19-month-old rats compared with

Table 2

Rat liver hydroxyproline content in the different age classes.

\begin{tabular}{ll}
\hline Age (months) & Hydroxyproline $(\mu \mathrm{g} / \mathrm{mg}$ tissue $)$ \\
\hline 2 & $0.238 \pm 0.032$ \\
6 & $0.222 \pm 0.013$ \\
12 & $0.219 \pm 0.049$ \\
19 & $0.297 \pm 0.025$ \\
\hline
\end{tabular}

Data are mean \pm SEM for five animals per age group. 


\section{collagen protein expression}

A) COL-I protein

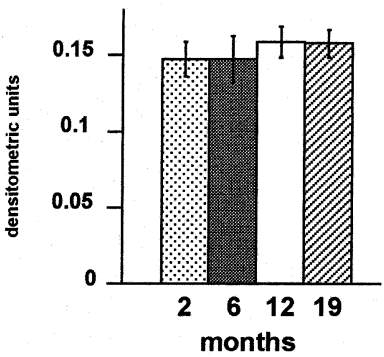

B) COL- III protein

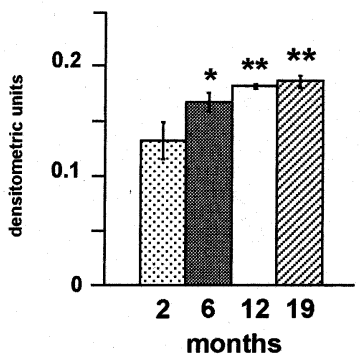

Fig. 4. Bar graph illustrating the age-dependent COL-I (a) and COL-III (b) protein levels in liver homogenates from rats aged 2, 6, 12 and 19-months. Data are reported as densitometric units after scanning of the immunoreactive bands. Values are mean \pm S.E.M. (five animals per age group). ${ }^{*} P<0.05,{ }^{* *} P<0.01$ vs. 2 -month-old rats.

a)

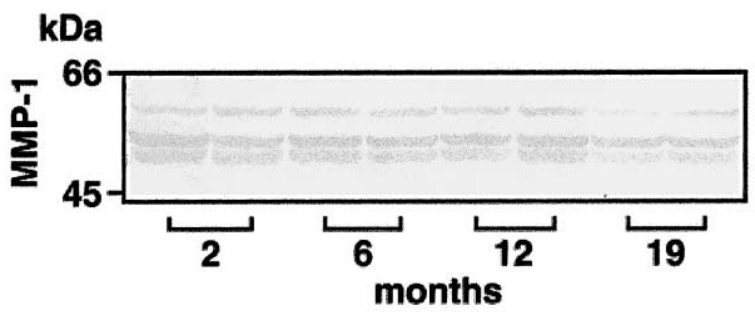

b)

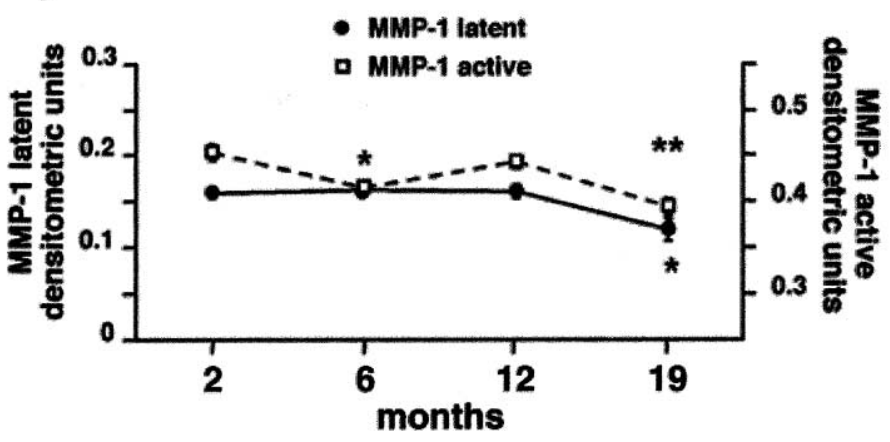

Fig. 5. Immunoreactive MMP-1 levels in liver extracts (40 $\mu \mathrm{g}$ of total proteins) of 2, 6, 12 and 19-month-old rats; each lane refers to a single animal. (a) Immunoblotting for MMP-1: there are positive bands in the $52 / 57 \mathrm{kDa}$ and in the $42 / 46 \mathrm{kDa}$ region corresponding to the proenzyme and to the active forms of MMP-1, respectively; (b) abundance of latent and active MMP-1 quantified by densitometric scanning. Data are mean \pm S.E.M. for five animals per age group. ${ }^{*} P<0.05,{ }^{* *} P<0.01$ vs. 2 -month-old rats.

the young ones (Fig. 5). A similar pattern was observed for MMP-2 activity (Fig. 6), where the decrease was $-18 \%(P<0.05),-20 \%(P<0.01)$ and $-23 \%(P<0.01)$ in the same age classes compared with the youngest rats. By contrast, gelatinase protein expression were found very sim- 
ilar during the considered life span (ANOVA $P=0.265)$.

TIMP-1 antibody localized a band in the 28 $\mathrm{kDa}$ region, consistent with this specie of TIMP. Additionally, a high-molecular weight immunoreactive band was observed at $50 \mathrm{kDa}$, corresponding to the TIMP-1/MMP-1 complex. TIMP-1 levels appeared almost unchanged at all the considered ages. By contrast, we observed an increase of the immunoreactive TIMP-1/MMP-1 complexes with age (2.5-fold increase in 19-month-old rats compared with the young ones) (Fig. 7).

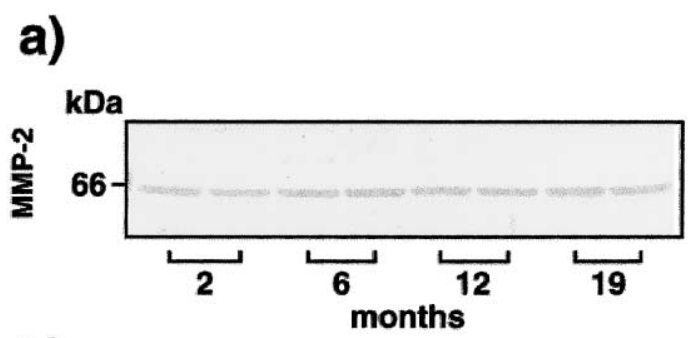

b)

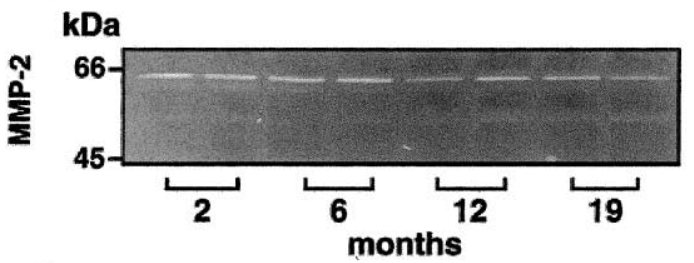

c)

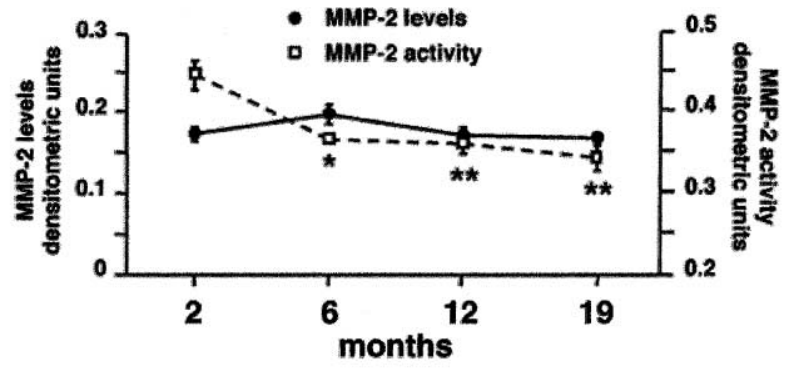

Fig. 6. MMP-2 in the liver of aging rats; each lane $(40 \mu \mathrm{g}$ of total proteins) refers to a single animal. (a) Immunoblotting: the antibody identifies a positive immunoreactive band in the $66 / 72 \mathrm{kDa}$ region corresponding to MMP-2; (b) representative gelatin zymogram of gelatinase activity: the lytic activity in the $66 / 72 \mathrm{kDa}$ region is consistent with MMP-2; (c) abundance of gelatinase activity after densitometric analysis. Data are mean \pm S.E.M. for five animals per age group. ${ }^{*} P<0.05$, $* * P<0.01$ vs. 2 -month-old rats.

\section{Liver \\ TIMP-1 expression}

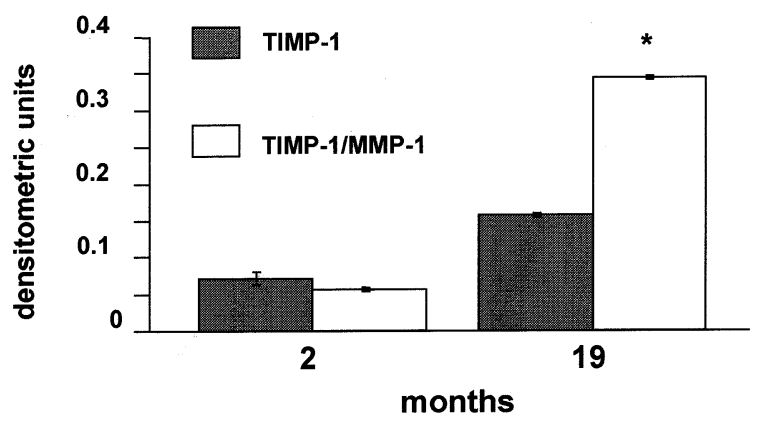

Fig. 7. TIMP-1 and TIMP-1/MMP-1 levels in young (2months) and old (19-months) rats after densitometric scanning. The antibody recognizes a $28 \mathrm{kDa}$ immunoreactive band consistent with this protein, and an additional $50 \mathrm{kDa}$ band corresponding to TIMP-1/MMP-1 complex. Data are mean \pm S.E.M. for five animals per age group. ${ }^{*} P<0.05$ vs. 2 -monthold rats.

\section{Discussion}

Sprague-Dawley rats showed continuous body growth between 2 and 19-months of age, with a consequent reduction of the $\mathrm{LW}$ to $\mathrm{BW}$ ratio between 2 and 12-months but no change thereafter. Since fibrosis impairs liver function and is pivotal in the modification of blood flow leading to portal hypertension, a better knowledge of the basic mechanisms that control this process would be useful. Data gathered to date have been obtained under pathological conditions, but little is known about progressive age-related changes. In the present report, we combined various analytical approaches and attempted to characterize the complex regulatory mechanisms that control collagen protein turnover in the aging liver.

We confirmed that collagen accumulated in the oldest animals with a specific histological method staining that revealed mild (mainly periportal) fibrosis. This observation is supported by the quantitative computerized image analysis and hydroxyproline measurements.

Irrespectively of the etiology, human liver fibrosis occurs with a prevalent increase in COL III 
content (Rauterberg et al., 1981), and a consequent reduction in type $\mathrm{I} /$ type III ratio. The same pattern is also described in $\mathrm{CCl}_{4}$-treated rats (Kucharz, 1987). Accordingly, the separate analysis of the two major interstitial COL proteins showed a prevalent increase of type III over the type I collagen in our study.

COL-I expression was upregulated both at the messenger and protein levels during aging. By contrast, we found opposite changes for COL-III steady-state mRNA levels, and COL-III protein deposition. This suggests different mechanisms of regulation for the two genes and, in particular, we can hypothesize, as possible steps of this dissociation, post-translational modifications such as the increase of molecular cross-links and/or an altered balance between synthesis and degradation.

In the same samples, TGF- $\beta 1$ mRNA levels were always barely detectable with our methods, probably unaffected by aging. The same situation was described in the heart and in the kidney where the age-related accumulation of interstitial and perivascular COL was not accompanied by significant changes in TGF- $\beta$ gene expression (Annoni et al., 1997; Gagliano et al., 2000). These data further support the hypothesis that age-dependent organ fibrosclerosis, including the liver, is unrelated to the significant of TGF- $\beta$. This conclusion is supported by the observation that TGF$\beta 1 \mathrm{mRNA}$ is not significantly expressed in normal livers and in situ hybridization detects few or no positive cells (Bedossa et al., 1995). By contrast, several studies have shown that TGF- $\beta 1$ gene expression is enhanced in experimental models of active fibroplasia and also in chronic liver pathology of humans (Annoni et al., 1992; Castilla et al., 1991; Milani et al., 1991).

COL levels are governed by the balance between synthesis and degradation, so the enhanced COL deposition in the liver of old rats could result from enhanced synthesis and/or slower breakdown rates (Arthur, 1990). However, few studies have looked closely into age-related changes in collagen degradation (Grasedyck et al., 1980; Mays et al., 1991a,b). COL catabolism is catalyzed by MMP, the proteolytic enzymes produced by lipocytes and other sinusoidal cells (Arthur et al., 1989, 1992). MMP with collagenase and gelatinase activities are secreted in the extracellular space as zymogens and are activated by proteolytic cleavage within the matrix environment; their activity is closely regulated and under pathological conditions any mismatch could result in excessive ECM accumulation or degradation (Arthur, 1990; Laurent, 1987).

Interstitial collagenase or MMP-1 cleaves the native triple helical region of interstitial COL into characteristic 3/4- and 1/4-collagen degradation fragments (Sakai and Gross, 1967; Woessner, 1991). The so-called gelatin fragments can be further degraded by less specific proteinases such as gelatinase or MMP-2 and stromelysin, leading to complete digestion of fibrillary COL. We found a significant decrease in liver proenzyme and active MMP-1 during maturation and aging, suggesting that interstitial COL may accumulate, because of changes in the balance between synthesis and degradation.

Zymography showed lower activity of MMP-2 in old animals compared with young ones. These findings are in apparent contrast with a previous study that showed increases in the latent and active MMP-2 activities in liver fibrosis induced by $\mathrm{CCl}_{4}$ (Takahara et al., 1995). However, aging is a slowly progressive phenomenon without inflammation-unlike $\mathrm{CCl}_{4}$ intoxication-and thus with a different balance in COL turnover. Moreover, protein degradation could be slower in aged rat, because of changes in COL cross-linking (Kanungo, 1980; Schaub, 1963), rendering the protein less susceptible to the action of proteases.

The extracellular activity of MMPs is tightly regulated at various steps, including inhibition by TIMPs. Among the four TIMPs identified to date (Denhardt et al., 1993; Brew et al., 2001) TIMP-1 and 2 are the most important, since they inhibit the active form of all MMPs (Denhardt et al., 1993; Woessner, 1991). TIMP-1 binds non-covalently to interstitial collagenase forming 1:1 stoichiometric TIMP-1/MMP-1 complexes that are not dissociated after SDS-PAGE (Thomas et al., 1998).

Recent studies underlined the possible role of TIMPs in liver fibrogenesis, showing that TIMP-1 gene and protein expression increase in clinical and experimental liver fibrosis (Herbst et al., 
1997; Benyon et al., 1996; Iredale et al., 1992, 1986). The monoclonal antibody we used (Thomas et al., 1998) recognizes TIMP-1 in the unbound form as well as when complexed to MMP. Whereas, unbound TIMP-1 was almost unaffected by aging, the inactive complex TIMP$1 /$ MMP-1 increased in the aged livers. This suggests that the low collagenase activity is consequent to decreased levels of MMP-1, concomitant with its increased inactivation by TIMP1.

However, this matter is still controversial since TIMP-1 overexpression in transgenic mices does not result in liver fibrosis (Yoshiji et al., 2000).

These findings as a whole indicate that aging is associated to moderate hepatic fibrosis especially within the portal tracts. This seems to occur without a prevalent role of one of the single mechanisms that control the ECM turnover, but rather as the consequence of dissociation between COL-I and COL-III gene regulation and decreased collagenolytic activity, enhanced by TIMP-1 inhibition. TGF- $\beta 1$, commonly involved in active fibroplasia, does not appear to play a significant role.

\section{Acknowledgements}

The authors thank Giorgia Ceva-Grimaldi (Istituto Clinico Humanitas, Italy) and Dr Luigi Flaminio Ghilardini (Milan University, Italy) for technical assistance. The present work was partially supported by grants from MURST 1998 (G.A.) and from the Associazione per la Ricerca Geriatrica e lo Studio della Longevitá (AGER, Italy).

\section{References}

Abrass, C.K., Adcox, M.J., Raugi, G.J., 1995. Aging-associated changes in renal extracellular matrix. Am. J. Pathol. 146, 742-752.

Angel, P., Baumann, I., Stein, B., Delius, H., Rahmsdorf, H.J., Herrlich, P., 1987. 12-O-tetradecanoyl-phorbol-13acetate induction of the human collagenase gene is mediated by an inducible enhancer element located in the 5'-flanking region. Mol. Cell. Biol. 7, 2256-2266.
Annoni, G., Weiner, F.R., Zern, M.A., 1992. Increased transforming growth factor $\beta 1$ gene expression in human liver diseases. J. Hepatol. 14, 259-264.

Annoni, G., Luvarà, G., Arosio, B., Gagliano, N., Fiordaliso, F., Santambrogio, D., Jeremic, G., Mircoli, L., Latini, R., Vergani, C., Masson, S., 1997. Age-dependent expression of fibrosis-related genes and collagen deposition in the rat myocardium. Mech. Ageing Dev. 101, 52-72.

Arthur, M.J.P., 1990. Matrix degradation in the liver. Semin. Liver Dis. 10, 47-55.

Arthur, M.J.P., Friedman, S.L., Roll, F.J., Bissell, D.M., 1989. Lipocytes from normal rat liver release a neutral metalloproteinase that degrades basement membrane (type IV) collagen. J. Clin. Invest. 84, 1076-1085.

Arthur, M.J.P., Stanley, A., Iredale, J.P., Rafferty, J.A., Hembry, R.M., Friedman, S.L., 1992. Secretion of 72 kDa type IV collagenase/gelatinase by cultured human lipocytes: analysis of gene expression, protein synthesis and proteinase activity. Biochem. J. 287, 701-707.

Bedossa, P., Peltier, E., Terris, B., Franco, D., Poynard, T., 1995. Transforming growth factor-betal (TGF- $\beta 1$ ) and TGF- $\beta 1$ receptors in normal, cirrhotic, and neoplastic human livers. Hepatology 21, 760-766.

Benyon, R.C., Iredale, J.P., Goddard, S., Winwood, P.J., Arthur, M.J., 1996. Espression of tissue inhibitor of metalloproteinases 1 and 2 is increased in fibrotic human liver. Gastroenterology 110, 821-831.

Biagini, G., Ballardini, G., 1989. Liver fibrosis and extracellular matrix. J. Hepatol. 8, 115-124.

Bradley, K.H., McConnell, S.D., Crystal, R.G., 1974. Lung collagen composition and synthesis. Characterization and changes with age. J. Biol. Chem. 249, 2674-2683.

Brew, K., Dinakarpandian, D., Nagase, H., 2001. Tissue inhibitors of metalloproteinases: evolution, structure and function. Biochim. Biophys. Acta 1477, 267-283.

Brinckerhoff, C.E., Plucinska, I.M., Sheldon, C.A., O'Connor, G.T., 1986. Half-life of synovial cell collagenase mRNA is modulated by phorbol myristate acetate but not by alltrans-retinoic acid or dexamethasone. Biochemistry 25, 6378-6384.

Burnette, W., 1981. Western Blotting': electrophoretic transfer of proteins from sodium dodecylsulfate-polyacrylamide gels to unmodified nitrocellulose and radiographic detection with antibody and radioiodinated protein A. Anal. Biochem. 112, 195-203.

Castilla, A., Prieto, J., Fausto, N., 1991. Transforming growth factors beta 1 and alpha in chronic liver disease. Effects of interferon alfa therapy. New Engl. J. Med. 324, 933-940.

Chomczynski, P., Sacchi, N., 1987. Single-step method of RNA isolation by acid guanidium thiocyanate-phenolchloroform extraction. Anal. Biochem. 162, 156-159.

Czaja, M.J., Weiner, F.R., Flanders, K.C., Giambrone, M.A., Wind, R., Biempica, L., Zern, M.A., 1989. In vitro and in vivo association of transforming growth factor- $\beta 1$ with hepatic fibrosis. J. Cell Biol. 108, 2477-2482.

Denhardt, D.T., Feng, B., Edwards, D.R., Cocuzzi, E.T., Malyankar, U.M., 1993. Tissue inhibitor of metallo- 
proteinases (TIMP, aka EPA): structure, control of expression and biological functions. Pharmacol. Ther. 59, 329341.

Dioguardi, N., Grizzi, F., Bossi, P., Roncalli, M., 1999. Fractal and spectral dimension analysis of liver fibrosis in needle biopsy specimens. Anal. Quant. Cytol. Histol. 21, 262-269.

Gagliano, N., Arosio, B., Santambrogio, D., Balestrieri, M.R., Padoani, G., Tagliabue, J., Masson, S., Vergani, C., Annoni, G., 2000. Age-dependent expression of fibrosisrelated genes and collagen deposition in rat kidney cortex. J. Gerontol. 55, B365-B372.

Grasedyck, K., Jahnke, M., Friedrich, O., Schulz, D., Linder, I., 1980. Aging of liver: morphological and biochemical changes. Mech. Ageing Dev. 14, 435-442.

Herbst, H., Wege, T., Milani, S., Pellegrini, G., Orzechowski, H.D., Bechstein, W.O., Neuhaus, P., Gressner, A.M., Schuppan, D., 1997. Tissue inhibitor of metalloproteinase1 and -2 RNA expression in rat and human liver fibrosis. Am. J. Pathol. 150, 1647-1659.

Herron, G.S., Banda, M.J., Clark, E.J., Gavrilovic, J., Werb, Z., 1986. Secretion of metalloproteinases by stimulated capillary endothelial cells. II. Expression of collagenases and stromelysin activities is regulated by endogenous inhibitors. J. Biol. Chem. 261, 2814-2818.

Iredale, J.P., Benyon, R.C., Arthur, M.J., Ferris, W.T., Alcolado, R., Winwood, P.J., Clark, N., Murphy, G., 1986. Tissue inhibitor of metalloproteinase-1 messenger RNA expression in enhanced relative to interstitial collagenase messenger RNA in experimental liver injury and fibrosis. Hepatology 24, 176-184.

Iredale, J.P., Murphy, G.M., Hembry, R.M., Friedman, S.L., Arthur, M.J.P., 1992. Human hepatic lipocytes synthesize tissue inhibitor of metalloproteinase-1. J. Clin. Invest. 90, 282-287.

Kanungo, M.S., 1980. Changes in collagen. In: Biochemistry of Ageing. Academic Press, New York, pp. 129-157.

Kleiner, D.E., Stetler-Stevenson, W.G., 1994. Quantitative zymography: detection of picogram quantities of gelatinases. Anal. Biochem. 218, 325-329.

Kucharz, E.J., 1987. Dynamics of collagen accumulation and activity of collagen degrading enzymes in the liver of rats with carbon tetrachloride induced hepatic fibrosis. Connect. Tissue. Res. 6, 143-151.

Laemnli, U.K., 1970. Cleavage of structural proteins during the assembly of the head of bacteriophage T4. Nature 227, 680-685.

Laurent, G.J., 1987. Dynamic state of collagen degradation in vivo and their possible role in regulation of collagen mass. Am. J. Physiol. 252, C1-C9.

Martinez-Hernandez, A., 1984. The hepatic extracellular matrix. I. Electron immunoistochemical studies in normal rat liver. Lab. Invest. 51, 57-74.

Martinez-Hernandez, A., Amenta, P.S., 1993. The hepatic extracellular matrix. Virchows Arch. A Pathol. Anat. 423, $1-11$.
Mays, P.K., Mc Anulty, R.J., Campa, J.S., Laurent, G.J., 1991a. Age-related changes in collagen synthesis and degradation in rat tissues. Importance of degradation of newly synthesized collagen in regulating collagen production. Biochem. J. 276, 307-313.

Mays, P.K., McAnulty, R., Laurent, G.J., 1991b. Age-related changes in total protein and collagen metabolism in rat liver. Hepatology 14, 1224-1229.

Milani, S., Herbst, H., Schuppan, D., Stein, H., Surrenti, C., 1991. Transforming growth factors beta 1 and beta 2 are differentially expressed in fibrotic liver disease. Am. J. Pathol. 139, 1221-1229.

Milani, S., Herbst, H., Schuppan, D., Grappone, C., Pellegrini, G., Pinzani, M., Casini, A., Calabru, A., Ciancio, G., Stefanini, F., Burroughs, A.K., Surrenti, C., 1994. Differential expression of matrix-metalloproteinase-1 and -2 genes in normal and fibrotic human liver. Am. J. Pathol. 144, 528-537.

Rauterberg, J., Voss, B., Pott, G., Gerlach, U., 1981. Connective tissue components of the normal and fibrotic liver. Klin. Wochenschr. 59, 767-779.

Rojkind, M., Giambrone, M.A., Biempica, L., 1979. Collagen types in normal and cirrhotic liver. Gastroenterology 76, $710-719$.

Sakai, T., Gross, J., 1967. Some properties of the products of reaction of tadpole collagenase with collagen. Biochemistry 6, 518-528.

Sakai, Y., Zhong, R., Garcia, B., Zhu, L., Wall, W.J., 1997. Assessment of the longevity of the liver using a rat transplant model. Hepatology 25, 421-425.

Sambrook, J., Fritch, E.F., Maniatis, T., 1989. Northern hybridization. In: Sambrook, J., et al. (Eds.), Molecular Cloning: a Laboratory Manual, Second ed. Cold Spring Harbor, New York, pp. 7.39-7.52.

Sastre, J., Pallardo, F.V., Pla, R., Pellin, A., Juan, G., O'Connor, J.E., Estrela, J.M., Miquel, J., Vina, J., 1996. Aging of the liver: age-associated mitochondrial damage in intact hepatocytes. Hepatology 24, 1199-1205.

Schaub, M.C., 1963. Qualitative and quantitative changes of collagen in parenchymatous organs of the rat during ageing. Gerontologia 8, 114-122.

Schmucker, D.L., 1998. Aging and the liver: an update. J. Gerontol. 53, B315-B320.

Schuppan, D., 1990. Structure of the extracellular matrix in normal and fibrotic liver: collagens and glycoproteins. Semin. Liver Dis. 10, 1-10.

Stageman, H., Stalder, K., 1967. Determination of hydroxyproline. Clin. Chim. Acta 18, 267-273.

Takahara, T., Furui, K., Funaki, J., Nakayama, Y., Itoh, H., Miyabayashi, C., Sato, H., Seiki, M., Ooshima, A., Watanabe, A., 1995. Increased expression of matrix metalloproteinase-II in experimental liver fibrosis in rats. Hepatology 21, 787-795.

Thomas, C.V., Coker, M.L., Zellner, J.L., Handy, J.R., Crumbley, A.J., Spinale, F.G., 1998. Increased matrix metalloproteinase activity and selective upregulation in LV myocardium from patients with end stage dilated cardiomiopathy. Circulation 97, 1708-1715. 
Tietz, N.W., Shuey, D.F., Wekstein, D.R., 1992. Laboratory values in fit aging individuals sexagenarians through centenarians. Clin. Chem. 38, 1167-1185.

Woessner, F.J., 1991. Matrix metalloproteinases and their inhibitors in connective tissue remodelling. FASEB J. 5, $2145-2154$.
Yoshiji, H., Kuriyama, S., Miyamoto, Y., Thorgeirsson, U.P., Gomez, D.E., Kawata, M., Yoshiji, J., Ikenaka, Y., Noguchi, R., Tsujinoue, H., Nakatani, T., Thorgeirsson, S.S., Fukui, H., 2000. Tissue inhibitor of metalloproteinases-1 promotes liver fibrosis development in a transgenic mouse model. Hepatology 32, 1248-1254. 